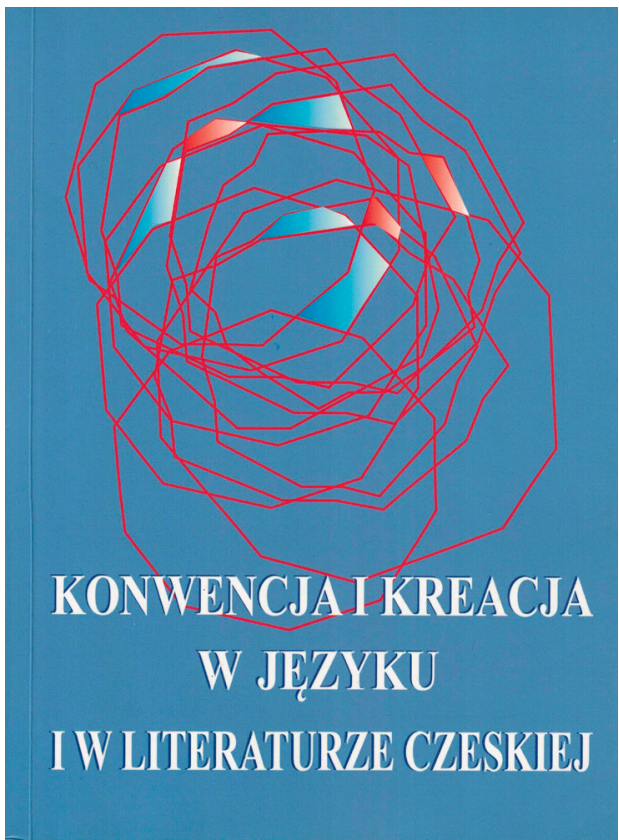

О.В. Гусева (Санкт-Петербург, Россия)

\section{Konwencja i kreacja w języku i literaturze czeskiej / Redakcja naukowa prof. dr hab. Mieczysław Balowski. Poznań: Instytut Filologii Słowiańskiej, Wydawnictwo PRO, 2020. 403 p. - \\ (Bohemica Posnaniensia, fasc. 24). ISBN 978-83-63090-33-3}

\begin{abstract}
Аннотация: Сборник статей «Конвенция и креация в чешском языке и литературе» продолжает серию, издаваемую польскими богемистами в Университете имени Адама Мицкевича в Познани под ред. проф. М. Балёвского. Сборник представляет интерес не только для славистов, но также для более широкого круга лингвистов, литературоведов и переводоведов, поскольку предлагает новый взгляд на проблему языковой и литературной конвенции и креации, которые выходят за рамки привычных «традиций» и «новаторства». Авторы включенных в сборник статей вводят в научный обиход новую терминологию и предлагают ее теоретическое и практическое обоснование на материале исследований чешской литературы, фольклора, грамматической системы, лексики и фразеологии, переводоведения и социально ориентированного дискурса. В статьях последовательно проводится мысль, что развитие языка, литературы и социума в целом - это непрерывный эволюционный процесс взаимодействия конвенционального и креативного подходов.
\end{abstract}

Ключевые слова: конвенция, языковая конвенция, креация, новаторство, славистика, чешский язык, чешская литература 


\title{
Convention and Creation in Czech Language and Literature / Scientific Editing by prof. dr hab. Mieczyslaw Balowski. Poznań: Institute of Slavic Philology, PRO Publishing House, 2020. 403 p. - (Bohemica Posnaniensia, fasc. 24).
}

\begin{abstract}
The collection of articles "Convention and Creation in Czech Language and Literature" continues the series published by the Polish Bohemians at the Adam Mickiewicz University in Poznań, edited by prof. M. Balowski. The collection is of interest not only for Slavists, but also for a wider range of linguists, literary critics and translation specialists as it offers a new look at the problem of linguistic and literary convention and creation, which go beyond the usual "traditions" and "innovation". The authors of the articles included in the collection introduce new terminology into scientific use and offer its theoretical and practical justification based on the research of Czech literature, folklore, grammatical system, vocabulary and phraseology, translation studies and socially oriented discourse. The articles consistently suggest that the development of language, literature, and society as a whole is a continuous evolutionary process of interaction between the conventional and creative approaches.
\end{abstract}

Key words: convention, language convention, creation, innovation, Slavic studies, Czech language, Czech literature

В сложном 2020 г. в Познани вышел в свет сборник научных статей «Конвенция и креация в чешском языке и литературе». Это очередной, уже двадцать четвертый сборник научной серии «Bohemica Posnaniensia”, издаваемой в Университете имени Адама Мицкевича польскими и чешскими богемистами. Научный редактор сборника и всей серии «Bohemica Posnaniensia" - профессор Мечислав Балёвский, польский славист и лингвист, заведующий кафедрой западнославянских языков и литератур Института славянской филологии Университета имени А. Мицкевича в Познани. Профессор Балёвский известен своими работами в области современного чешского языка, западнославянской ономастики и фразеологии, а также межкультурной коммуникации.

Среди авторов сборника богемисты Карлова университета в Праге, Университета Градец-Кралове, Западночешского университета в Пльзене, Оломоуцкого университета, Масарикова университета в Брно, Остравского университета, Университета Яна Пуркине в Усти-над-Лабем, Института чешского языка Чешской академии наук, Университета имени А. Мицкевича в Познани, Силезского университета в Катовицах.

Несмотря на тематическую направленность всей познанской серии и данного сборника, он представляет большой интерес не только для богемистов, поскольку поднятая в нем проблема имеет концептуальный теоретический характер и будет интересна широкому кругу лингвистов и литературоведов. В статьях сборника последовательно разрабатывается новая терминология, раскрывается значение понятий «конвенция» и «креация» в языкознании, литературоведении и социально ориентированном дискурсе. Польский сборник расширяет возможности употребления данного понятия и предлагает системный, комплексный подход к интерпретации понятий «конвенция» и «креация», которые оказываются шире привычных «традиции», «творчества» или «новаторства». 
Сборник состоит из введения и четырех частей, в которых последовательно рассматриваются проблема конвенции и креации в чешской литературе, грамматической системе, лексике и фразеологии и, наконец, в системе коммуникации. В сборник вошли статьи на польском и чешском языках.

Ключевой для понимания концепции всего сборника стала статья Мечислава Балёвского - научного редактора сборника и всей серии «Bohemica Posnaniensia», опубликованная во Введении. В статье «Конвенция и креация как движущая сила развития языка» ${ }^{1}$ Балёвский предлагает собственное понимание явлений «конвенции» и «креации», вынесенных в заглавие сборника. Они выходят за рамки лингвистической или литературоведческой проблематики и затрагивают различные аспекты жизни социума. В начале статьи проф. Балёвский обращается к дефинициям слова «конвенция» в словарях польского языка. В польском языке это слово имеет следующие значения:

konwencja 1. общепринятые в какой-либо среде нормы поведения, образ мыслей и т. п.; 2. комплекс черт, характерных для художественных произведений, принятый автором; 3. международный договор, предусматривающий соблюдение сторонами юридических обязательств; 4. предвыборный съезд членов политической партииㄹ․

Как мы видим, значение польского слова «конвенция» шире, чем в русском, где «конвенция», согласно Толковому словарю русского языка под редакцией Ожегова, означает «Международный договор по какому-нибудь определенному вопросу»³. При этом российское языкознание под «языковой конвенцией» понимает соглашение, принятое в языковом сообществе относительно способов построения, значения и употребления языковых выражений. Термин «конвенциональность» употребляется в культурологии и социологии и означает «неотъемлемое качество культурного объекта, приобретаемое им в результате признания за ним (вследствие установления согласия между участниками социокультурного взаимодействия) определенного набора устойчивых характеристик, выделенных в качестве значимых» ${ }^{4}$.

Среди российских исследователей на материале логики и философии математики понятие конвенции рассматривал философ, писатель и переводчик В.В. Целищев ${ }^{5}$. В семиотическом аспекте к языковой конвенции обращался М.В. Лебедев ${ }^{6}$. Проблема языковой конвенции в отечественной науке продолжает привлекать внимание исследователей. В польском языкознании и литературоведении одной из первых понятие конвенции и конвенциональности начала рассматривать Изидора Домбска. . Однако до сих пор понятие «конвенция» не является однозначным в польской научной среде, например, слово «конвенция», а также образованные от него производные «конвенциональный», «конвенциональность» в научных работах часто используются в значении «традиционный», «общепринятый», «понятный» и не имеют терминологического значения.

\footnotetext{
${ }^{1}$ Balowski M. Konwencja i kreacja jako siła napędowa rozwoju języka // Konwencja i kreacja w języku i literaturze czeskiej. Poznań: Instytut Filologii Słowiańskiej, Wydawnictwo PRO, 2020. S. 17-34.

${ }^{2}$ Wielki Słownik Języka Polskiego. URL: wsjp.pl/index.php?id_hasla=34594\&ind=0\&w_szukaj=konwenсја (дата обращения: 22.03.2021).

3 Толковый словарь С. Ожегова. URL: slovarozhegova.ru/word.php?wordid=11657 (дата обращения: 22.03.2021).

4 Этнопсихологический словарь. URL: ethnopsychology.academic.ru/148/конвенциональность (дата обращения: 22.03.2021).

${ }^{5}$ Целищев В.В. Конвенция // Проблемы логики и методологии науки. Новосибирск: Наука, 1982. С. 7-42.

${ }^{6}$ Лебедев М.В. Стабильность языкового значения. М.: Эдиториал УРСС, 1998.

${ }^{7}$ Dambska I. O konwencjach i konwencjonalizmie. Wrocław: Zakład Narodowy im. Ossolińskich, 1975.
} 
Еще сложнее обстоит ситуация со словом «креация». Балёвский подчеркивает, что в научной литературе встречается разное понимание этого термина. В толковых словарях польского языка «креация» определяется следующим образом:

kreacja 1. творчество, созидание чего-то нового; 2. создание чего-либо нового в искусстве, особенно в литературе; 3. роль в фильме или театральной постановке, оригинально и интересно сыгранная актером; 4. элегантный наряд, особенно женский ${ }^{1}$.

Во всех этих значениях при переводе на русский язык мы выберем разные соответствия. В двух первых значениях польское слово близко к русскому понятию «созидание, создание». Во втором это, скорее, «артистизм», а в третьем - «наряд, одеяние». Все эти значения объединяет наличие творческого подхода, изобретательности, креативности. В толковом словаре Ожегова слово «креация» отсутствует. При этом в российской лингвистике термин «креация» появился уже давно. Его использует, например, А.Ф. Журавлев в своей статье «Технические возможности русского языка в области предметной номинации» и дает такую дефиницию: «креация - изобретение произвольного немотивированного знака» ${ }^{2}$.

Таким образом, мы видим, что в чешской, польской и российской науке существует необходимость появления четких дефиниций терминов «конвенция» и «креация». Эту задачу и призван решить сборник Познанского университета «Конвенция и креация в чешском языке и литературе». Авторы статей, опубликованных в сборнике, многократно подчеркивают, что «конвенцию» и «креацию» нельзя определить как «традицию» и «новаторство»: это понятия более широкие и не противопоставленные, но связанные, переплетающиеся друг с другом. В языке всегда присутствуют и «конвенциональность» и «креативность».

Анализируя понятие «конвенция», Балёвский обращается к философии, где конвенция рассматривается в рамках теории познания, а также к пониманию конвенции в семиотике и формальной логике. В этих науках, при всей разнице подходов, понимание термина «конвенция» подразумевает соглашение, договоренность, узус, общепринятый порядок действий. Все эти значения присутствуют и в языковой конвенции. Подобным соглашением являются, например, нормативные учебники языка, которые представляют собой результат договоренности на определенную тему нескольких сторон: лингвистов, учителей и министерства образования. К литературным конвенциям можно отнести единство места и времени в классической драме. Балёвский кратко прослеживает эволюцию понимания конвенциональности в языкознании: от древнегреческих философов, которые первыми попытались определить отношения между вещами и словами, их обозначающими, через дискуссии, которые велись о конвенциональности языковых знаков в языкознании и философии XVIIXIX вв., и до современных точек зрения на конвенциональность языка. Балёвский рассматривает работы современных польских лингвистов, посвященные языковым

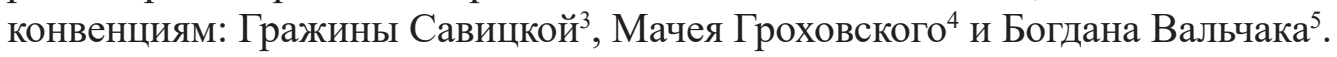

\footnotetext{
${ }^{1}$ Wielki Słownik Języka Polskiego URL: wsjp.pl/index.php?id_hasla=8963\&ind=0\&w_szukaj=kreacja (дата обращения: 22.03.2021).

2 Журавлёв А.Ф. Технические возможности русского языка в области предметной номинации // Способы номинации в современном русском языке. М.: Наука, 1982. С. 45.

${ }^{3}$ Sawicka G. Udział konwencji w kształtowaniu się odmian języka // Język trzeciego tysiąclecia III. Tom 1. Tendencje rozwojowe współczesnej polszczyzny / Red. Grzegorz Szpila. Kraków: Tertium, 2005. S. 181-197. ${ }^{4}$ Grochowski M. Konwencje semantyczne a definiowanie wyrażeń językowych. Warszawa: Zakład Semiotyki Logicznej UW, 1993. 116 s.

${ }^{5}$ Walczak $B$. Czy w odniesieniu do języka konwencjonalność i kreacyjność przeciwstawiają się sobie? // Konwencja i kreacja w języku, literaturze i narracji historycznej / Red. Małgorzata Karwatowska, Robert Litwiński, Adam Siwiec. Lublin: Wydawnictwo Uniwersytetu Marii Curie-Skłodowskiej, 2016. S. 37-44.
} 
Г. Савицкая определяет конвенцию как вид договора, применяемого к комплексу семиотических систем, охватывающих принятые в обществе нормы поведения, реализуемые с применением знаков, характерных для каждой системы. Для этого договора характерны следующие признаки: 1) он априорен (не зависит от опыта), 2) он не записан (хотя и необязательно; например, кодексы различных обществ существуют в письменной форме), 3) он обязателен, что означает, что за его нарушением следуют санкции (отсутствие одобрения). Применительно к языку Г. Савицкая выделяет две группы конвенций: общественно-культурные и «чисто» языковые (структурные, семантические, референционные и прагматические), при этом языковые конвенции вытекают из общественно-культурных конвенций как знакового, так и коммуникативного уровня (например, стилистические конвенции $)^{1}$. В качестве примера языковой конвенции, проистекающей из общественно-культурной, исследовательница приводит принцип номинации и написания антропонимов. Те же виды языковых конвенций (грамматические, семантические, референционные и прагматические) выделяет М. Гроховский. Балёвский отмечает, что для языковых конвенций характерны три аспекта влияния: 1. нормативный аспект; 2. семантико-коммуникационный аспект; 3. узуальный аспект. Это своего рода механизмы, упорядочивающие языковую картину окружающего нас мира.

Языковые конвенции могут обладать разной степенью конвенционализации: от слабой, нестабильной или фрагментарной до сильной, обязательной, стабильной. Так, к сильным конвенциям относятся грамматическая, референционная и прагматическая конвенции, а к слабым - стилистические и жанровые конвенции. Нарушение языковой конвенции - обязательное условие эволюции данной системы. Благодаря отрицанию конвенции рождается языковая креативность. Акт креации, созидания, противопоставлен существующим образцам, шаблонам и матрицам. Креативность требует рефлексии над языковыми конвенциями. К языковой креации нас подталкивает развитие цивилизации, научно-технический прогресс, новые культурные явления. Как пример креативности, которая меняет сложившуюся в языке конвенцию, можно привести явление делексикализации, метафоризации, метонимизации, ресемантизации, заимствования и создание неологизмов. На уровне текста это стирание жанровых границ.

Авторы сборника неоднократно подчеркивают, что конвенция и креация не исключают, но дополняют друг друга. Конвенция, понимаемая как установленный способ действий, обычаев, традиций, обогащается креацией, за которой стоит творческий, продуктивный стиль мышления и действия. Эту мысль Виктор Виктора развивает в статье «Модель истории чешской литературы гуманистического периода - конвенция или креативность?»². Автор показывает, что формирование концепции истории чешской литературы началось еще в эпоху Возрождения и было связано с именами Й. Добровского, Й. Юнгманна и А. Шемберы, оно было продолжено во второй половине XIX в., а затем развито в XX в. Каждый из исследователей вносил что-то новое в историографию литературы, но вместе с тем он опирался на результаты исследований своих предшественников. В современном литературоведении накопилось много новых материалов и методологических подходов для переосмысления достигнутых результатов и подготовки новой

\footnotetext{
${ }^{1}$ Sawicka G. Udział konwencji w kształtowaniu się odmian języka. S. 184.

${ }^{2}$ Viktora $V$. Model dějin české literatury humanistického období - konvence, nebo kreativita? // Konwencja i kreacja w języku i literaturze czeskiej. Poznań: Instytut Filologii Słowiańskiej, Wydawnictwo PRO, 2020. S. 9-16.
} 
академической истории чешской литературы. В этой работе конвенция и креация должны идти рука об руку. Отказ от традиций в пользу новаторства повлечет за собой утрату преемственности, игнорирование человеческого фактора, невозможность достижения компромисса и, в результате, отказ от собственных корней, от своего прошлого.

Эту же проблему в языковом ключе поднимает Мария Чехова в статье «Пуризм с точки зрения условности и новаторства в языке. Только путь от пуризма к антипуризму или путь от пуризма к пуризму?» ${ }^{2}$. Автор делает вывод, что следование языковым конвенциям любой ценой не способствует здоровому развитию языка, языковой пуризм, в конечном счете, обедняет язык. Антипуризм, понимаемый как новаторство, креативность в языке, является следствием глобализации и дает импульс для дальнейшего развития языка.

Истоки народных традиций можно найти и в фольклоре. Их влияние на современную литературу анализирует Сватава Урбанова в статье «Фольклор как источник и парадокс подлинности»². Исследовательница пишет о «новом фольклоризме» - творческом преобразовании аутентичных традиций на фоне возрождения интереса к фольклору - и показывает это на примере анализа произведений современных чешских авторов.

Конвенции и креации в чешской литературе посвящены включенные в сборник статьи Иво Харака, Бохуслава Хоффманна, Хелены Хасиловой и других исследователей. Проблему конвенции и креации в контексте перевода рассматривают Любомир Хампл и Диана Свободова. Отдавая себе отчет в конвенциональности значений тех или иных лексем в повседневной языковой коммуникации, переводчик проявляет креативность в поисках соответствующих звуковых эквивалентов в языке перевода. О конвенции и креации в языке современных пользователей Интернета пишет Хелена Хилова. В сборнике приводятся различные примеры языковой креативности: в грамматической системе, в лексике и фразеологии, в лингводидактике и переводоведении, в художественной литературе и литературоведении. Авторы отмечают, что невозможно перечислить все способы языковой креации, как и все действующие в данный период конвенции. К созданию новых средств выражения отправителя подталкивает тот факт, что существующие конвенции не в состоянии передать специфики отправляемого сообщения, его содержания или формы. Цель языковой креативности состоит в вовлечении рецептора в процесс декодирования смысла, провоцировании его к сознательному нарушению конвенции. И это непрерывный эволюционный процесс, происходящий на уровне языка и сознания.

\section{ЛИТ Е РАТ У РА}

1. Журавлёв А.Ф. Технические возможности русского языка в области предметной номинации // Способы номинации в современном русском языке. М.: Наука, 1982. С. 45-108.

2. Лебедев М.В. Стабильность языкового значения. М.: Эдиториал УРСС, 1998. 167 с.

3. Толковый словарь С. Ожегова. URL: slovarozhegova.ru/word.php?wordid=11657 (дата обращения: 22.03.2021).

\footnotetext{
${ }^{1}$ Čechová M. Purismus z pohledu konvence a inovace v jazyce. Cesta jen od purismu k antipurismu, nebo cesta od purismu k purismu? // Konwencja i kreacja w języku i literaturze czeskiej. Poznań: Instytut Filologii Słowiańskiej, Wydawnictwo PRO, 2020. S. 151-162.

${ }^{2}$ Urbanová $S$. Folklor jako zdroj i paradox autenticity // Konwencja i kreacja w języku i literaturze czeskiej. Poznań: Instytut Filologii Słowiańskiej, Wydawnictwo PRO, 2020. S. 37-50.
} 
4. Этнопсихологический словарь. URL: ethnopsychology.academic.ru/148/конвенциональность (дата обращения: 22.03.2021).

5. Целищев В.В. Конвенция // Проблемы логики и методологии науки. Новосибирск: Наука, 1982. С. 7-42.

6. Balowski M. Konwencja i kreacja jako siła napędowa rozwoju języka // Konwencja i kreacja w języku i literaturze czeskiej. Poznań: Instytut Filologii Słowiańskiej, Wydawnictwo PRO, 2020. S. 17-34.

7. Čechová $M$. Purismus z pohledu konvence a inovace v jazyce. Cesta jen od purismu $\mathrm{k}$ antipurismu, nebo cesta od purismu k purismu? // Konwencja i kreacja w języku i literaturze czeskiej. Poznań: Instytut Filologii Słowiańskiej, Wydawnictwo PRO, 2020. S. 151-162.

8. Dambska I. O konwencjach i konwencjonalizmie. Wrocław: Zakład Narodowy im. Ossolińskich, $1975.151 \mathrm{~s}$.

9. Grochowski M. Konwencje semantyczne a definiowanie wyrażeń językowych. Warszawa: Zakład Semiotyki Logicznej UW, 1993. 116 s.

10. Sawicka G. Udział konwencji w kształtowaniu się odmian języka // Język trzeciego tysiąclecia III. Tom 1: Tendencje rozwojowe współczesnej polszczyzny / Red. Grzegorz Szpila, Kraków: Tertium, 2005. S. 181-197.

11. Urbanová S. Folklor jako zdroj i paradox autenticity // Konwencja i kreacja w języku i literaturze czeskiej. Poznań: Instytut Filologii Słowiańskiej, Wydawnictwo PRO, 2020. S. 37-50.

12. Viktora $V$. Model dějin české literatury humanistického období - konvence, nebo kreativita? // Konwencja i kreacja w języku i literaturze czeskiej. Poznań: Instytut Filologii Słowiańskiej, Wydawnictwo PRO, 2020. S. 9-16.

13. Walczak B. Czy w odniesieniu do języka konwencjonalność i kreacyjność przeciwstawiają się sobie? // Konwencja i kreacja w języku, literaturze i narracji historycznej / Red. Małgorzata Karwatowska, Robert Litwiński, Adam Siwiec. Lublin: Wydawnictwo Uniwersytetu M. Curie-Skłodowskiej, 2016. S. 37-44.

14. Wielki Słownik Języka Polskiego. URL: wsjp.pl/index.php?id_hasla $=34594 \& i n d=0 \& w$ szukaj=konwencja (дата обращения: 22.03.2021).

\section{REFERENCES}

1. Balowski M. Convention and Creation as a Driving Force for Language Development. In: Convention and Creation in Czech Language and Literature. Poznań. Institute of Slavic Philology Press, PRO Publishing House. 2020, pp. 17-34.

2. Čechová M. Purism from the Point of View of Convention and Innovation in Language. The Path Only from Purism to Antipurism, or the Path from Purism to Purism?. In: Convention and Creation in Czech Language and Literature. Poznań. Institute of Slavic Philology Press, PRO Publishing House. 2020, pp. 151-162.

3. Dąmbska I. (1975) On Conventions and Conventionalism. Wrocław. Zakład Narodowy im. Ossoliński Press. 151 p.

4. Ethnopsychological Dictionary. URL: ethnopsychology.academic.ru/148/конвенциональность (date accessed: 22.03.2021).

5. Explanatory Dictionary of the Russian Language by S. Ozhegov. URL: slovarozhegova. ru/word.php?wordid=11657 (date accessed: 22.03.2021).

6. The Great Dictionary of the Polish Language. URL: wsjp.pl/index.php?id_hasla=34594\& ind $=0 \&$ w_szukaj=konwencja (date accessed: 22.03 .2021 ). 
7. Grochowski M. (1993) Semantic Conventions and Definition of Linguistic Expressions. Warszawa. Zakład Semiotyki Logicznej UW Press. 116 p.

8. Lebedev M.V. (1998) Stability of Linguistic Meaning. Moscow. Editorial URSS. 167 p.

9. Sawicka G. The Role of the Convention in the Formation of Language Varieties. In: The Language of the Third Millennium III. Volume 1: Developmental Tendencies of the Contemporary Polish Language / Ed.: Grzegorz Szpila. Kraków. Tertium Publ. 2005, pp. 181-197.

10. Tselishchev V.V. Convention. In: Problems of Logic and Methodology of Science. Novosibirsk. Nauka Publ. 1982, pp. 7-42.

11. Urbanová S. Folklore as a Source and Paradox of Authenticity. In: Convention and Creation in Czech Language and Literature. Poznań. Institute of Slavic Philology Press, PRO Publishing House. 2020, pp. 37-50.

12. Viktora V. Model of the History of Czech Literature of the Humanistic Period - Conventions or Creativity? In: Convention and Creation in Czech Language and Literature. Poznań. Institute of Slavic Philology Press, PRO Publishing House. 2020, pp. 9-16.

13. Walczak B. Do Conventionality and Creativity Contradict Oppose Each Other with Regard to Language? In: Convention and Creation in Language, Literature and Historical Narration / Ed.: Małgorzata Karwatowska, Robert Litwiński, Adam Siwiec. Lublin. M. Curie-Skłodowska University Press. 2016, pp. 37-44.

14. Zhuravlev A.F. Technical Capabilities of the Russian Language in the Field of Subject Nomination. In: Methods of Nomination in the Modern Russian Language. Moscow. Nauka Publ. 1982, pp. 45-108.

Сведения об авторе:

Ольга Валерьевна Гусева,

канд. филол. наук

доцент

филологический факультет

Санкт-Петербургского государственного университета
Olga V. Guseva,

$\mathrm{PhD}$

Associate Professor

Philological Faculty

Saint-Petersburg State University

o.guseva@spbu.ru 